\title{
The effects of prenatal exposure to a 900 megahertz electromagnetic field on hippocampus morphology and learning behavior in rat pups
}

\author{
Ayşe İkincia*, Ersan Odacı $^{a}$, Mehmet Yıldırım ${ }^{\text {, Haydar Kaya }}{ }^{\mathrm{c}}$, Metehan Akça ${ }^{\mathrm{b}}$, Hatice Hancı ${ }^{\mathrm{a}}$, Ali Aslan ${ }^{\mathrm{d}}$ \\ Osman Fikret Sönmez ${ }^{\mathrm{e}}$, Orhan Baş ${ }^{\mathrm{f}}$
}

${ }^{a}$ Department of Histology and Embryology, Faculty of Medicine, Karadeniz Technical University, Trabzon, Turkey

${ }^{b}$ Department of Physiology, Faculty of Medicine, Karadeniz Technical University, Trabzon, Turkey

${ }^{c}$ Department of Electrical and Electronics Engineering, Faculty of Engineering, Karadeniz Technical University, Trabzon,

Turkey

${ }^{d}$ Department of Physiology, Faculty of Medicine, Sakarya University, Sakarya, Turkey

${ }^{e}$ Department of Neurosurgery, Education and Research Hospital, Samsun, Turkey

${ }^{f}$ Department of Anatomy, Faculty of Medicine, Ordu University, Ordu, Turkey

\section{ARTICLE INFO}

\section{* Correspondence to:}

Ayşe İkinci

Department of Histology and Embryology, Faculty of Medicine,

Karadeniz Technical University,

Trabzon, Turkey

e-mail: ayse_ikinci@hotmail.com

\section{Keywords:}

Electromagnetic field

Hippocampus

Learning behavior

Rat

\section{ABSTRACT}

This study was planned to examine the effect on hippocampus morphology and learning behavior in rat pups exposed to a 900 megahertz (MHz) electromagnetic field (EMF) in the prenatal period. Sprague Dawley rats weighing 180-250 $\mathrm{g}$ at the beginning of the study and with a regular cycle were left to mate with male rats. The following day, rats identified as pregnant using the vaginal smear test were divided into two groups; control $(n=3)$ and $\operatorname{EMF}(n=3)$. No procedure was performed in the control group. The EMF group was exposed to $900 \mathrm{MHz}$ EMF for $1^{\mathrm{h}}$ per day on days 13 to 21 of pregnancy. Female rat pups were removed from their mothers at 21 days old. Two newborn rat groups were then established, a 13 member control group and a 10 member EMF group. We foresaw that maternal separation anxiety might develop in the rat pups, and behavioral tests commenced 4 days later. Radial arm maze and passive avoidance tests measuring learning and memory performance and the open field test to evaluate locomotor activities were applied. All rats were decapitated on the $32^{\text {nd }}$ day of the study and brain tissues removed. These were fixed in paraffin and underwent routine histological tissue analyses. Sections were taken, stained with Cresyl fast violet and subjected to histopathological examination. Positive effects on learning behavior were determined in the EMF group rats in the radial arm maze $(\mathrm{p}=0.007)$ and passive avoidance $(\mathrm{p}=0.037)$ tests, administered to both groups under identical conditions, while no statistically significant difference was determined in the open field test $(\mathrm{p}=0.05)$ results. The absence of any statistical difference in the open field test shows that the animals were not exposed to any stress during application of the test. No pathology was determined in the control group at histopathological examination of the sections. In contrast, neuronal and morphological compromise was observed in the EMF group. Our results show that exposure to a $900 \mathrm{MHz}$ EMF in the prenatal period had an adverse effect on female pups learning behavior and also caused histopathological changes in the hippocampus.

J.Exp.Clin.Med., 2013; 30: 278 